injection of the suspect ampicillin. This batch of ampicillin was taken out of circulation immediately, and samples were sent for analysis in Europe. Chemical analysis confirmed the presence of ampicillin but also of high concentrations of $N$, $\mathrm{N}$-dimethylanalin, a degradation product, and of another, unknown, substance.

Culture showed Pseudomonas spp and an unknown organism in the first two phials and Bacillus spp and an unknown organism in the second two phials. The laboratory suggested that, in view of the unevenness of the contamination, the route of entry could have been the perforated stoppers. The non-government organisation informed the relevant authorities.

The fact that the aluminum seals of the phials were normal while the rubber stoppers were perforated indicates that the rubber stoppers were not perforated after the manufacturing process. Thus stoppers that were already perforated were probably used in the manufacturing process. The most likely explanation is that these stoppers were second hand-in other words, disposable material had been reused. In the Indian subcontinent it is common (and dangerous) practice to collect used disposable syringes and needles from hospitals and to repackage them and sell them as new-hopefully after proper cleaning and sterilisation.

As far as I know, reuse of disposable stoppers has not been described before, but it seems possible that it is a new, illegal, probably profitable, but certainly highly dangerous enterprise.

HARRY JEENE

Kabul Medical Institute,

Afghanistan

h.jeene@lshtm.ac.uk

\section{Alcohol consumption and risk of coronary heart disease}

\section{Studies suggest that wine has additional effect to that of ethanol}

Edror,- - In their review of the reduction in the risk of coronary heart disease due to moderate alcohol consumption Eric B Rimm and colleagues interpret the available studies as supporting a beneficial effect of alcohol without any additional effect of the specific beverage consumed (beer, wine, or spirits). ${ }^{1}$ We do not challenge the paradigm that ethanol itself possesses some cardioprotective properties. In the Copenhagen city heart study we also found a reduction in mortality associated with occasional intake of all three types of beverage. ${ }^{2}$ But studies that do not take into account all three types of beverage are not suitable for addressing the question of whether there is an additional effect of beer, wine, or spirits.

Rimm and colleagues included in their review 10 prospective population studies, of which three did not analyse the effect of all three types of alcoholic beverage because consumption of one or two of them was negligible. In two other studies the analysis did not take into account the intake of the other types of beverage. Of the remaining five studies, four suggested a greater beneficial effect of wine, although with different methodological and statistical strength. In Rimm et al's study, which found a stronger beneficial effect of spirits, $12.2 \%$ of the male health professionals studied reported a total alcohol intake of more than 2 drinks a day. ${ }^{3} \mathrm{~A}$ breakdown of the figures showed that the number of subjects who drank each type of beverage were small. The exact data are not given, but we are told that spirits were the beverage most frequently consumed, and the broad confidence intervals give a hint of the small number of subjects in the groups that drank beer and wine. ${ }^{3}$
Thus the ecological and prospective cohort studies, as well as pertinent clinical studies, ${ }^{4}$ suggest that wine has an additional effect to that of ethanol in reducing the risk of coronary heart disease.

MORTEN GRØNBEK

Senior research fellow

THORKILD I A SøRENSEN

Danish Epidemiology Science Centre, Professo Institute of Preventive Medicine, Copenhagen University Hospital, Kommunehospitalet, DK-1399 Copenhagen $\mathrm{K}$, Denmark

1 Rimm EB, Klatsky A, Grobbee D, Stampfer MJ. Review of moderate alcohol consumption and reduced risk of coronary heart disease: is the effect due to beer, wine, or spirits? $B M 7$ 1996;312:731-6. (23 March.)

2 Grønbæk M, Deis A, Sørensen TIA, Becker U, Schnohr P, Jensen $G$. Mortality associated with moderate intake of Jensen $G$. Mortality associated with moder
wine, beer, or spirits. $B M$ I $^{\prime} 1995 ; 310: 1165-9$.

3 Rimm EB, Giovannucci EL, Willett WC, Colditz GA, Asherio A, Rosner B, et al. Prospective study of alcohol consumption A, Rosner B, et al. Prospective study of alcohol consumption
and risk of coronary disease in men. Lancet and risk of

4 Criqui MH, Rigel BL. Does diet or alcohol explain the French paradox?. Lancet 1994;344:1719-23.

Frankel EN, Kanner J, German JB, Parks E, Kinsella JE. Inhibition of oxidation of human low-density lipoprotein by phenolic substances in red wine. Lancet 1993;341:454-7.

\section{Authors' reply}

EDITOR,-Many of the prospective studies that we reviewed could not take into account all of the three main beverages containing alcohol (beer, wine, and spirits) because of the limited frequency of consumption of some of them. We do not agree with Mørten Gronbæk and Thorkild I A Sørensen, however, that this should necessarily prevent them from being included in a review of the benefits of moderate alcohol consumption. In the multivariate analysis of type of beverage in the Copenhagen study the authors examined the association between wine consumption and total mortality, holding the effects of spirits and beer constant statistically. However, in the Honolulu heart study, in which beer accounted for almost all of the alcohol consumed, ${ }^{2}$ and in the Italian rural cohort study, ${ }^{3}$ in which only wine was consumed, the effects of other types of beverage were held constant implicitly.

Arguably, studies looking at only a single type of beverage may be more informative than those looking at many, since measurement of each beverage may contain error due to overreporting or underreporting or differential error due to differences in drinking patterns. The inverse association reported between moderate beer consumption and coronary heart disease in the Honolulu heart study (relative risk 0.57 ) was similar to the inverse association reported for wine in the Copenhagen city heart study (relative risk 0.47 (95\% confidence interval 0.35 to 0.62 ) and for spirits in the study from eastern Finland (0.3 $(0.1$ to 0.7$))^{4}$

Gronbæk and Sørensen state that they do not challenge the paradigm that ethanol has some cardioprotective properties. In their study, however, 1-2 drinks of spirits a day increased the risk of death from coronary heart disease $(1.16$ (0.98 to 1.39)). ${ }^{1}$ If the ethanol in spirits reduced the risk of coronary heart disease to a degree similar to that reported for beer consumption in their study (0.79 (0.68 to 0.91$)$ ) then some other, unknown, component of spirits must have been almost doubling the risk of death from coronary heart disease among men and women consuming 1-2 drinks a day. This seems unlikely since most other studies have reported a significant inverse association between moderate consumption of spirits and coronary heart disease. ${ }^{4}$ Therefore, differences in relative risks between types of beverage in the Copenhagen study, and in many other studies, are more likely to have been due to differences in lifestyle characteristics, such as diet and drinking patterns, than to any additional substantial benefit from the non-ethanol components of a specific beverage. Assistant professor of epidemiology and nutrition MEIR J STAMPFER Professor of epidemiology and nutrition

Harvard School of Public Health,

Boston, MA 02115,

USA

ARTHUR KLATSKY Senior consultant in cardiology

Kaiser Permanente Medical Center, Oakland, CA,

USA

DEDERICK GROBBEE Professor of epidemiology

Department of Epidemiology and Biostatistics,

Erasmus Unifersity Medical School,

Rotterdam,

Netherlands

1 Granbak M, Deis A, Sorensen TIA, Becker U, Schnohr P, Jensen G. Mortality associated with moderate intakes of Jensen G. Mortality associated with moder
wine, beer, or spirits. $B M Y 1995 ; 310: 1165-9$.

2 Yano K, Rhoads GG, Kagan A. Coffee, alcohol and risk of coronary heart disease among Japanese men living in Hawaii. N Engl F Med 1977;297:405-9.

3 Farchi G, Fidanza F, Mariotti S, Menotti A. Alcohol and mortality in the Italian rural cohorts of the seven countries study. Int $\mathcal{F}$ Epidemiol 1992;21:74-81.

4 Rimm EB, Klatsky A, Grobbee D, Stampfer MJ. Review of moderate alcohol consumption and reduced risk of coronary heart disease: is the effect due to beer, wine, or spirits? BMF 1996;312:731-6. (23 March.)

\section{Association cannot be assumed to be causal}

EDrToR,-The Royal College of Physicians has estimated that alcohol is responsible for 25000 premature deaths every year. ${ }^{1}$ Medical professionals need to be cautious about making pronouncements that might encourage people to drink more. Two recent papers in the $B M \mathcal{F}$ that seem to provide evidence of a protective effect of alcohol in relation to ischaemic heart disease ${ }^{23}$ were widely reported in the national media; it may be assumed that the net effect will be to shift upwards the distribution of alcohol consumption in the population.

Neither study provides convincing evidence that alcohol protects against heart disease. Association cannot be assumed to be causal, but the authors of both articles make this assumption. Eric B Rimm and colleagues write that "a substantial portion of the benefit is from alcohol."2 Hans Ole Hein and colleagues discuss attributable risk among men who abstained from alcohol; this term is appropriate only to a causal relation. ${ }^{3}$

There are reasons to doubt a causal relation. In Hein and colleagues' study non-drinkers were older than drinkers, which suggests a lower all cause mortality. Subsequent higher mortality might be attributable to age, which would have a non-linear relation with mortality and therefore be inadequately controlled for in the regression. The authors did not analyse data from the 1971 baseline, and mortality related to alcohol before 1986 may have biased the sample. The authors dismiss the possibility of "sick quitters" causing bias but do not consider a possible "sick non-starter" effect, whereby those prone to heart disease never started drinking. Given that $87 \%$ of the non-drinkers had never drunk, this was potentially a much larger source of bias.

Rimm and colleagues base their claim for a causal relation on inconsistent observational data. Of 12 ecological studies cited, seven show a significant beneficial effect of wine, two show a harmful effect of beer, and only one shows a beneficial effect of spirits and one a beneficial effect of beer. Of three case-control studies, only one shows all forms of alcohol to be protective; 
and one shows all forms of alcohol to be harmful. Of 10 cohort studies, only one shows a consistent significant benefit for all forms of alcohol. Ecological studies are least prone to confounding by sick non-drinkers and are the least supportive of the theory that alcohol may protect against heart disease.

We question the wisdom of publishing these papers without giving any form of public health advice. They will be perceived by the public as giving a signal to consume more alcohol.

LUKE WHITAKER

Research statisticia HELEN WARD Senior lecture

Department of Epidemiology and Public Health,

Imperial College School of Medicine at St Mary's,

London W2 1 PG

1 Royal College of Physicians. The medical consequences of alcohol abuse: a great and growing evil. London: Tavistock, 1987.

2 Rimm EB, Klatsky A, Grobbee D, Stampfer MJ. Review of moderate alcohol consumption and reduced risk of coronary heart disease: is the effect due to beer, wine, or spirits? BMF 1996;312:731-6. (23 March.)

3 Hein HO, Suadicani P, Gyntelberg F. Alcohol consumption, serum low density lipoprotein cholesterol concentration, and risk of ischaemic heart disease: six year follow up in the Copenhagen male study. BMF 1996:312:736-41. (23 March.)

\section{Authors' reply}

EDrToR,-The proposal that alcohol has a protective effect on the risk of ischaemic heart disease no longer has the charm of novelty. Frontline research should now attempt to identify those people who benefit from drinking alcohol and those who do not.

We investigated the interplay between alcohol consumption, serum low density lipoprotein cholesterol concentration, and risk of ischaemic heart disease. The strength of the association between alcohol and risk was highly dependen on the low density lipoprotein cholesterol concentration: the higher the concentration the stronger the inverse association. There was no association among men with a low low density lipoprotein cholesterol concentration (defined as those with concentrations in the lowest fifth, < $3.63 \mathrm{mmol} / \mathrm{l}$ )

For obvious reasons, studies on alcohol and risk must be natural experiments. Accordingly, it is not possible to conclude whether associations are causal. Suggestive of causality are a set of criteria accounted for in our study, such as temporality, strength of association, and biological plausibility. ${ }^{12}$

The possibility of bias also has to be considered. Non-drinkers were older than drinkers. In regression analyses we took into accoun the possibility of a non-linear relation between age and risk. Including age as a continuous variable, a dichotomous variable, or several five year age group dummy variables had no influence on the results. Non-drinking was not simply a proxy for old age, suggesting increased risk. A bias caused by "sick non-starters" seems unlikely. We excluded all men with overt cardiovascular disease at the baseline, and relevant electrocardiographic changes were equally distributed among drinkers and abstainers. We discussed other potentially biasing factors in our paper and a previous one. ${ }^{3}$

The $B M \mathcal{F}$ is not a health magazine for the public. In our paper we did not attempt to deviate from the hypothesis advanced. We did not discuss the well known potential risks and side effects of alcohol consumption since public health advice was not the issue. In a liberal society with a free press it is generally not possible to prevent the public from misinterpreting scientific results.

In his editorial Ian $\mathbf{R}$ White claims that our hypothesis has been tested before. ${ }^{4}$ No previous study has analysed the interaction of alcohol, low density lipoprotein cholesterol concentration, and risk, presenting data on the association between alcohol and risk stratified by different levels of lipid concentrations. Another claim is that our findings could be the result of chance. That is possible. We agree that the results of one epidemiological study can never stand alone.

H O HEIN

Associate professor

P SUADICANI Senior researcher F GYNTELBERG Professor

Copenhagen Male Study,

Epidemiological Research Unit,

7122 Rigshospitalet,

DK-2200 Copenhagen N,

Denmark

1 Hill $\mathrm{AB}$. The environment and disease: association or causation? Proc R Soc Med 1965;58:295-300.

2 Rothmann KJ. Modern epidemiology. Boston: Little, Brown, 1986.

3 Hein HO, Sørensen H, Suadicani P, Gyntelberg F. Alcohol consumption, Lewis phenotypes, and risk of ischaemic heart disease. Lancet 1993;341:392-6.

4 White IR. The cardioprotective effects of moderate alcohol consumption. BMF 1996;312:1179-80. (11 May.)

\section{Review of interventions should help to reduce inequalities in health}

EdroR,-Graham C M Watt ${ }^{1}$ accuses us of being perverse in our review of interventions that health services could use to help reduce inequalities in health. ${ }^{2}$ We made clear, as he does, that socioeconomic factors are likely to have more influence on variations in health status than are health services. That does not mean, however, that aspects of health services are not influential in widening inequalities or that the resources of the NHS cannot be used to help reduce them.

Our review and its subsequent extensions ${ }^{3}$ identified over 100 studies evaluating ways in which health services alone or in collaboration with other agencies could make some positive contribution in this area. For example, a rigorous study of intensive control of blood pressure showed that it was effective in reducing social class differences in mortality, ${ }^{4}$ and a variety of health, social, and nutritional interventions aimed at the general population or targeted at low income groups were shown to improve children's health.

Watt's other criticism-that "evidence based medicine from randomised controlled trials is least likely to emerge from areas of social deprivation"-is unclear. If he means that trials of treatments do not usually include deprived populations and so their results cannot be applied, this would imply denying these populations access to treatments of generally proved effectiveness, so increasing inequality. If he means that such trials are not appropriate for assessing methods for reducing inequalities in health, we would counter that a number of health care and social interventions have been evaluated with randomised controlled trials, which have provided important and reliable evidence that can be used by policymakers. For example, a trial of negative income tax showed a large and significant effect on birth weight. ${ }^{5}$ Our reviews, however, did not confine themselves to randomised controlled trials but systematically identified relevant experimental and quasiexperimental studies and summarised the results of major observational studies. ${ }^{23}$

Watt makes the unstartling observation that we need to tackle social deprivation. If we concentrate solely on macro policy there is the danger that NHS decision makers will be let off the hook and social justice allowed to slip off their agenda. Our review provides a useful sum- mary of potentially effective interventions that may fall within the scope of the NHS. While this approach might not have such political cachet as that adopted by Watt, we think that disadvantaged populations have a right to benefit from the application of the results.

VIKKI ENTWISTLE

Research fellow IAN WATT

Senior research fellow

NHS Centre for Reviews and Dissemination,

University of York

York YO1 5DD

1 Watt GCM. All together now: why social deprivation matters to everyone. BMF 1996;312:1026-9. (20 April.)

2 NHS Centre for Reviews and Dissemination. Review of the research on the effectiveness of health service intervemtions to research on the effeciuenss of health service interventions reduce variations in health. York: NHS Cent

3 Arblaster L, Lambert M, Entwistle V, Forster M, Fullerton D, Sheldon TA, et al. A systematic review of the effectiveness of health service interventions aimed at reducing inequalities in health. Fournal of Health Services Research and Policy 1996;1:93-103.

4 Stamler R, Hardy RJ, Payne GH, Tyroler HA, Tung B, Newman B, et al. Educational level and 5 year all cause mortality following health education of hypertensive patients. Am F Public Health 1983;73:153-61.

5 Kehner BH, Wolin CM. Impact of income maintenance on low birth weight: evidence from the Gary experiment. fournal of Human Resources 1980;14:434-62.

\section{Time for a ban on landmines}

\section{Workload resulting from landmine injuries} is huge burden on hospitals

EDITOR,-One aspect of the epidemic of antipersonnel landmines ${ }^{1}$ that is often overlooked is the implication for the indigenous surgical services of the constant flow of injuries caused by the mines. ${ }^{2}$ The countries affected are the ones least able to help themselves, with surgical provisions already stretched to the limit. Few figures exist on the epidemiology of landmine injuries and the workload these impose on local services, as most of the data have been gleaned from Red Cross hospitals dealing solely with war injuries. ${ }^{3}$

Last year, while working in Angola, I conducted an audit of the surgical admissions to Kuito General Hospital. Of 795 admissions over 10 months, 211 were due to war-type injuries inflicted on civilians. Landmine injuries accounted for 82 of these. Most of the rest were gunshot wounds. War injuries, whether caused by landmines or high velocity rounds, use a disproportionately large amount of surgical time and resources in comparison with civilian-type trauma. ${ }^{4}$ Each injury frequently requires two or three operations. The patients with war injuries who were admitted accounted for $42 \%$ of the general and orthopaedic operations carried out during the study period (268/643). The consequences of such an influx of patients for a British hospital are almost unthinkable.

Such a large burden of work detracts from the ability of local surgeons to care for patients with non-traumatic conditions. In addition, the resulting large population of young people with amputated limbs becomes an economic burden on the society as a whole: a one legged man cannot feed his family, and a one legged woman cannot look after her children. In Kuito an average of six people a month lose their legs because of landmine injuries. Such an incidence would tax the resources of a district general hospital in Britain; the effect on Kuito is disastrous.

EDDIE CHALONER

Royal London Hospital,

Registrar in surgery

London E1 1BB

Pearn J. Landmines: time for an international ban. $B M$ 1996;312:990-1. (20 April.)

Chaloner EJ, Mannion SJ. Anti-personnel mines: the global epidemic. Ann R Coll Surg Engl 1995;77:1-4. 